\title{
Aproximación al desarrollo económico local en el Municipio de Santa María Ostuma, Departamento de La Paz, El Salvador: propuestas y acciones
}

Approach to local economic development in the Municipality of Santa Maria Ostuma, Department of La Paz , El Salvador: proposals and actions

\author{
Oscar Ayala Tejada* \\ oscareayala03@hotmail.com \\ Guillermo Gutiérrez Montoy** \\ guillermo@udb.edu.sv \\ Elsy Melchor Guevara*** \\ elsy03mg@hotmail.com \\ Jesús Aníbal Rodas $* * * *$ \\ anibal.rodaz@hotmail.com
}

Licenciado en Administración de Empresas. Investigador y Técnico. Alcaldía Municipal de Santa María Ostuma, Departamento de La Paz, El Salvador.

** Doctor en Ciencias Empresariales. Docente- Investigador. Facultad de Ciencias Económicas, Universidad Don Bosco, El Salvador.

**** Licenciada en Administración de Empresas. Encargada de la Unidad de Desarrollo Local. Alcaldía Municipal de Santa María Ostuma, Departamento de La Paz, El Salvador.

***** Técnico en Desarrollo Local e investigador. Alcaldía Municipal de Santa María Ostuma, Departamento de La Paz, El Salvador. 


\title{
Resumen
}

El presente estudio presenta los hallazgos de la investigación realizada en el Municipio de Santa María Ostuma, Departamento de La Paz, El Salvador. Su objetivo consistió en analizar el desarrollo local y la gestión municipal en Santa María Ostuma, con énfasis en el sector panelero de la región, el cual es un sector con gran potencial en la zona, tanto productivo como de atractivo turístico, y que traería para el pueblo ingresos, empleo y desarrollo en la comunidad. Para el desarrollo de la investigación se realizaron visitas in situ a los productores de panela, así como entrevistas a los actores claves involucrados.

\section{Palabras clave}

Desarrollo local, Santa María Ostuma, turismo, panela, caña de azúcar, gestión municipal.

\begin{abstract}
This study presents the findings of research conducted in the Municipality of Santa Maria Ostuma, Department of La Paz, El Salvador. Its aim was to analyze local development and municipal management in Santa Maria Ostuma, with emphasis on the panela sector in the region, which is a sector with great potential in the area, both productive and touristic attraction, and that would bring the people income, employment and community development. For the development of research in situ, panela producers were visited and interviews with key stakeholders were performed.
\end{abstract}

\section{Keywords}

Local development, Santa María Ostuma, tourism, panela, sugar cane, municipal management.

Forma sugerida de citar: Ayala Tejada, Oscar Eliseo, Gutiérrez Montoya, Guillermo Antonio, Melchor Guevara, Elsy Esther, \& Rodas, Jesús Aníbal (2015). Aproximación al desarrollo económico local en el Municipio de Santa María Ostuma, Departamento de La Paz, El Salvador. Propuestas y acciones. Revista Retos, 10(2), pp.123-134.

\section{Introducción}

El Municipio de Santa María Ostuma (MSMO) se encuentra ubicado en el Departamento de La Paz, el topónimo de "Ostuma" es donde hay barrancos o hay cuevas, y obtuvo el título de villa el 10 de abril de 1912. Posee una extensión territorial de $24,12 \mathrm{~km}_{2}$ y según el censo del 2007, una población de 5990 habitantes. La actividad principal es el cultivo de árboles frutales, a tal grado que en junio se desarrolla la "Feria de la Piña", un evento único en El Salvador.

Un instrumento valioso lo representa el Índice de Competitividad Municipal (2011), al cual el Municipio de Santa María Ostuma se incorporó por primera ocasión, y en la siguiente tabla se observan los resultados del ICM con sus nueve indicadores: 


\section{Tabla 1 : ICM y Sub-Índices. Comparación del Municipio de Santa María Ostuma, 2011}

\begin{tabular}{|c|c|c|c|c|c|c|c|c|c|c|}
\hline 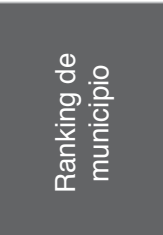 & $\underline{\underline{O}}$ & 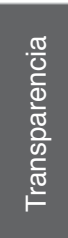 & 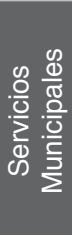 & 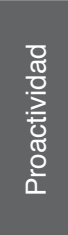 & 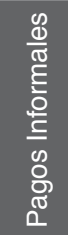 & 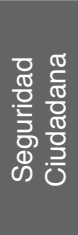 & 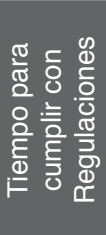 & 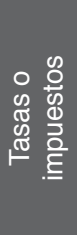 & 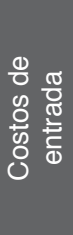 & 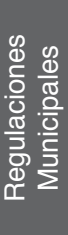 \\
\hline Comasagua & 5.59 & 5.78 & 3.76 & 4.88 & 7.23 & 6.94 & 5.02 & 4.13 & 8.91 & 5.65 \\
\hline $\begin{array}{c}\text { Santa María } \\
\text { Ostuma }\end{array}$ & 5.53 & 5.25 & 2.41 & 4.86 & 7.37 & 8.36 & 4.32 & 6.06 & 8.34 & 5.18 \\
\hline $\begin{array}{c}\text { Santa Cruz } \\
\text { Michapa }\end{array}$ & 5.39 & 4.31 & 4.64 & 2.89 & 7.26 & 6.37 & 4.89 & 4.31 & 9.73 & 6.24 \\
\hline
\end{tabular}

Fuente: Índice de Competitividad Municipal, 2011

Santa María Ostuma aparece bien posicionada en los indicadores de seguridad ciudadana y tasas e impuestos municipales, no así en indicadores como servicios municipales y tiempo para cumplir con las regulaciones. El ICM muestra una radiografía del municipio, y presenta las áreas en donde se debería trabajar para mejorar la competitividad de todo el municipio, tanto en la microrregión de los Nonualcos como a nivel de país.

\section{Estrategia de desarrollo económico local del Municipio de Santa María Ostuma}

A nivel conceptual, no existe una definición única sobre lo que entenderemos por Desarrollo Económico Local (DEL). Albuquerque (2004) señala que el DEL:

Se trata de un proceso participativo y llevado a cabo por un acuerdo de actores locales orientado a lograr la mejora del ingreso y las condiciones y calidad de vida de la gente que vive en un determinado ámbito territorial. Por consiguiente, lo primero que hay que señalar es que no se trata de la aplicación de políticas nacionales en los ámbitos regional, provincial o municipal. El desarrollo económico local requiere que las estrategias sean elaboradas a partir de la movilización y participación activa de los actores territoriales.

En otras palabras, el DEL se trata de un enfoque cuyo origen se encuentra en la "base" o "desde abajo", y no en la "cima" o "desde arriba" (léase Gobierno Central). Pero también señala Albuquerque (2004) que el territorio debe comprenderse con el conjunto de "actores y agentes" (público, privado y sociedad en general) que lo conforman, quienes toman un rol protagónico en la búsqueda del desarrollo de la región.

Cruz y otros (2015) agregan que "las comunidades rurales que habi- 
tan estos espacios están en constante búsqueda de alternativas productivas para mejorar sus medios de vida y cuidar el ambiente el cual está sufriendo deterioro", y acá el énfasis ocurre en el cuido del medio ambiente, para contrarrestar los efectos del actual cambio climático.

Agregado a lo anterior, Zapata $(2008 b)$ presentó un diagnóstico en el cual plantea que las principales áreas problemáticas de la Región de los Nonualcos, zona en la que se encuentra ubicado el Municipio de Santa María Ostuma, son:

- Ausencia de integración urbana en Zacatecoluca, San Juan Nonualco, Santiago Nonualco y San Rafael Obrajuelo.

- Limitada protección de recursos naturales en el borde costero.

- Limitado aprovechamiento productivo en la zona del aeropuerto.

- Potencial turístico en la carretera panorámica desaprovechado.

- Relaciones de intercambio no aprovechadas con las regiones $\mathrm{La} \mathrm{Li}$ bertad y Usulután.

- Falta de conectividad entre el norte y el sur de la Región.

- Peligros por deslizamientos en las zonas altas y de inundaciones en las zonas bajas.

La municipalidad propuso un plan DEL que tiene un periodo de ejecución de mediano plazo, desde el año 2008 hasta el año 2012¹. La alcaldesa señala que, para que los

1 Ídem. sectores productivos del territorio puedan participar en las convocatorias de proyectos del CODENOL, los productores o iniciativas productivas debían estar asociadas, por lo que la alcaldía ha impulsado y apoyado a la conformación de las asociaciones de carpinteros, de mujeres emprendedoras, de paneleros y una red juvenil ${ }^{2}$. De hecho, el fomento del "emprendimiento femenino" en la zona es de suma relevancia, ya que por ejemplo, la investigación realizada por G. Gutiérrez (2013) refleja que de cada diez emprendimientos en El Salvador, seis son liderados por mujeres y cuatro por hombres, en tanto que la motivación para emprender, de cada diez emprendimientos, cuatro son creados para aprovechar una "oportunidad" y seis se desarrollan por "necesidad".

Las líneas de acción esbozadas en el Plan son las siguientes ${ }^{3}$ :

- Fortalecimiento del tejido empresarial y su vinculación con mercados dinámicos.

- Fomento del espíritu emprendedor y creación de nuevos emprendimientos.

- Institucionalización gradual y continua de los procesos, sistemas e instrumentos municipales de fomento al desarrollo económico local, con pasos e instan-

2 Entrevista realizada a Elsa Antonia Guevara, Alcaldesa de Santa María Ostuma. Realizada el martes 25 de octubre de 2012.

3 Entrevista realizada a Elsa Antonia Guevara, Alcaldesa de Santa María Ostuma. Realizada el martes 25 de octubre de 2012. 
cias claramente identificados y que privilegien iniciativas sostenibles y responsables fiscalmente.

- Estímulo y gestión de recursos financieros para el fortalecimiento de tejido empresarial que realizan agentes económicos en el municipio.

- Impulso a un enfoque de desarrollo económico sostenible y equitativo en el municipio, articulado a las políticas y programas nacionales que afectan el fomento del desarrollo económico.

- Desarrollo de normativas municipales para el fomento del desarrollo económico local.

Se determina, además, que es necesaria la aprobación de una ordenanza municipal, la cual será el medio que garantice la vigencia del proceso de aplicación de la Política ${ }^{4}$. Además de los instrumentos de desarrollo económico local impulsados desde la Alcaldía, también es importante hacer referencia a dos iniciativas importantes. La primera es la feria de la piña que la Alcaldía en conjunto con APPES lleva a cabo cada año; y en segundo lugar el proyecto que el CONAMYPE desarrolla actualmente y se denomina "Un pueblo, un producto" . Cada año, el Municipio de Santa María Ostuma celebra la Fe-

4 Entrevista realizada a Elsa Antonia Guevara, Alcaldesa de Santa María Ostuma. Realizada el martes 25 de octubre de 2012.

5 Diario Digital Contrapunto. "Un pueblo, un producto, un orgullo", en http://www.contrapunto.com.sv Consultada el 27 de febrero de 2012 . ria de la Piña, cuyo objetivo consiste en promover el patrimonio agrícola del municipio: la piña. Además, con esta iniciativa se pretende estimular el turismo del territorio y fomentar el mercadeo local de la piña.

Por otra parte, queremos recalcar los beneficios que representa el modelo del Cooperativismo, y que traería también mayores logros en el desarrollo de la producción y habitantes de Santa María Ostuma. En palabras de la expresidenta de Costa Rica (2010-2014), Laura Chinchilla, afirmaba que "el modelo del cooperativismo ofrece respuestas como ningún otro para librar a nuestros pueblos de los embates del hambre, de la pobreza y de la inseguridad alimentaria, en un mundo globalizado que socializa todas las crisis, en tiempos del cambio climático" ${ }^{\prime \prime}$. Además, agregó la Presidenta que el cooperativismo puede ser uno de los principales factores para promover el desarrollo sostenible y la competitividad de los pequeños productores.

\section{¿Un asocio público-privado en Santa María Ostuma?}

El Desarrollo Económico Local se fundamenta en la necesidad de la población de que se creen alternativas para la generación de empleo, desarrollo de cadenas productivas, fortalecimiento de la economía familiar y promoción de la inversión público-

6 Discurso de la expresidenta de Costa Rica, Laura Chinchilla, el 29 de mayo de 2012 en la FAO, Roma, Italia. 
privada. Se construye teniendo a la base un pacto social entre los actores de un territorio determinado que han definido un objetivo común (CODENOL, 2008).

Los actores públicos y privados de los Nonualcos se encuentran trabajando en desarrollar nuevas formas asociativas dentro de la región, por ejemplo, existen dos mesas de concertación público-privado (CODENOL, 2008), en dos sectores priorizados: pesca y turismo, así como la implementación del enfoque de cadenas de valor como un instrumento importante de la promoción del desarrollo económico local.

En síntesis, se sabe que uno de los principales factores de éxito de un proceso de desarrollo económico local es el fomento de las alianzas público-privadas (CODENOL, 2008). Dentro de las condiciones necesarias para un asocio público privado se citan a continuación (Quant Dueñas y otros, 2011):

- Estabilidad macroeconómica y compromiso político: el concesionario no debe tener que renegociar el contrato con cada cambio de gobierno.

- Marco Legal favorable: distintas modalidades de legislación, como concesiones, contratos de asociación, joint ventures, asociación en participación.

- Eficiencia de los organismos reguladores.
- Experiencia en estructuración de contratos y estructuras financieras

- Experiencia en promoción de inversiones.

\section{Metodología}

Nuestro estudio se concentrará en analizar al sector panelero de Santa María Ostuma, así como detectar alternativas para su pleno desarrollo ${ }^{7}$, y además evaluaremos la incidencia de la gestión municipal en el desarrollo local del pueblo. El sector panelero tiene mucho potencial de crecimiento para la región, e incidencia directa en la generación de empleo, ingresos y afluencia turística (véase Lara Coto y otros, 2012). La metodología empleada fue cualitativa, y los instrumentos utilizados fueron entrevistas a actores claves (productores y gobierno local) y observación directa de los productores de panela. La investigación de campo se llevó a cabo entre septiembre y octubre de 2012, realizando las visitas los fines de semana, en jornadas de diez horas diarias. Para lograr llegar a todos los productores de panela, el equipo investigador de dividió en parejas, y así se avanzó más rápidamente en la recogida de la investigación de campo.

7 La "panela" o atado dulce, chancaca (del quechua chankaka), es un alimento típico de muchos países, principalmente de América. La Organización de las Naciones Unidas para la Agricultura y Alimentación (FAO) registra la panela como "azúcar no centrifugado" 


\section{Resultados}

El diagnóstico realizado al sector panelero refleja que hay muchas deficiencias en infraestructura, notorio deterioro de herramientas e incluso muchas desigualdades entre los paneleros, equipos y procedimientos. Se cuenta con moliendas ubicadas en una ruta de pasos accesibles y cercanos entre ellas, pero a la fecha no se ha explotado esta condición. Además, siendo un sector importante para la dinamización de la economía y creación de fuentes de empleo, a la fecha no se han realizado iniciativas ni existe mayor énfasis en cerrar las brechas que permitan un verdadero cambio, con pautas e indicadores que permitan ir avanzando en la mejora de la calidad de vida de los habitantes.

En el Municipio, el área cultivada es de 145.38 manzanas, con una producción total de 935 toneladas de caña de azúcar. Se cuenta con un productor de azúcar y setenta y cinco productores de panela. Existen a la fecha cinco moliendas de trapiche y veintitrés moliendas con motor, con condiciones de infraestructura variables, ya que cinco presentan "muy buenas" condiciones, siete tienen condiciones "buenas", diez presentan condiciones "regulares" y seis tienen condiciones de infraestructura "malas". A la fecha existen 261 personas que se emplean en el rubro panelero del Municipio, distribuidos así: 58 mujeres, 103 hombres, 75 jóvenes y 25 adultos mayores.

$\mathrm{Al}$ investigar al sector panelero, nos encontramos con las siguientes falencias:

- Falta de estándares de calidad y buenas prácticas en el procesamiento, para cumplir con los requisitos sanitarios exigidos para el comercio y la exportación.

- Fomento del espíritu emprendedor y creación de nuevos emprendimientos.

- Estímulo y gestión de recursos financieros para el fortalecimiento de tejido empresarial que realizan agentes económicos en el municipio.

- Impulso a un enfoque de desarrollo económico local y equitativo en el municipio, articulado a las políticas y programas nacionales que afectan el fomento del desarrollo económico.

- Desarrollo de normativas Municipales para el fomento del desarrollo económico local.

Como parte del diagnóstico, se presenta a continuación una matriz FODA elaborada por el equipo de trabajo, tomando como referencia a la Municipalidad de Santa María Ostuma: 
Tabla 2. Matriz de estrategias FODA, Municipio de Santa María Ostuma

\begin{tabular}{|c|c|c|}
\hline $\begin{array}{l}\text { AMBIENTE INTERNO / } \\
\text { AMBIENTE EXTERNO }\end{array}$ & OPORTUNIDADES & AMENAZAS \\
\hline & $\begin{array}{l}\text { - Alta demanda en la produc- } \\
\text { ción de la piña. } \\
\text { - Apoyo por parte de diferen- } \\
\text { tes instituciones nacionales e } \\
\text { internacionales. } \\
\text { - Iniciativas para comercia- } \\
\text { lizar la producción fuera del } \\
\text { municipio. } \\
\text { - Interés de la ONGs para } \\
\text { gestionar recursos del muni- } \\
\text { cipio. } \\
\text { - Política de turismo a nivel } \\
\text { nacional. } \\
\text { - Apertura por parte de la mu- } \\
\text { nicipalidad para la creación } \\
\text { de leyes en beneficio de los } \\
\text { jóvenes. }\end{array}$ & $\begin{array}{l}\text { - Plagas que afectan los } \\
\text { cultivos. } \\
\text { - Competencia desigual } \\
\text { con competidores exter- } \\
\text { nos. } \\
\text { - Producto mal pagado. } \\
\text { - Vulnerabilidad del te- } \\
\text { rritorio por su condición } \\
\text { topográfica. } \\
\text { - Deterioro ambiental }\end{array}$ \\
\hline FORTALEZAS & $\begin{array}{c}\text { DEFINICIÓN DE } \\
\text { ESTRATEGIAS OFENSIVAS } \\
\text { (FO) }\end{array}$ & $\begin{array}{l}\text { DEFINICIÓN DE } \\
\text { ESTRATEGIAS } \\
\text { DEFENSIVAS (FA) }\end{array}$ \\
\hline $\begin{array}{l}\text { - Abundante producción y } \\
\text { diversificación de árboles fru- } \\
\text { tales. } \\
\text { - Buen clima de altura. } \\
\text { - Vías de acceso principales } \\
\text { en buen estado. } \\
\text { - Existe una planta de com- } \\
\text { postaje. } \\
\text { - Existe involucramiento de } \\
\text { los jóvenes. } \\
\text { - Inclusión de la mujer en las } \\
\text { actividades productivas en el } \\
\text { municipio. } \\
\text { - Bajos niveles de delincuen- } \\
\text { cia en el Municipio. } \\
\text { - Apoyo del gobierno local a } \\
\text { las iniciativas. } \\
\text { - Buen sistema educativo. } \\
\text { - La feria de la piña se ha con- } \\
\text { vertido en una actividad de } \\
\text { impacto regional y nacional. } \\
\text { - Buen servicio de transporte } \\
\text { público de pasajeros. }\end{array}$ & $\begin{array}{l}\text { - Fomento de proyectos em- } \\
\text { prendedores impulsados por } \\
\text { jóvenes y potenciados por la } \\
\text { municipalidad con visión de } \\
\text { desarrollo socioeconómico } \\
\text { del municipio. } \\
\text { - Posicionar al Municipio de } \\
\text { - Santa María Ostuma como } \\
\text { un referente nacional en la } \\
\text { producción y comercializa- } \\
\text { ción de frutas. } \\
\text { - Desarrollo de alianzas estra- } \\
\text { tégicas con instituciones pú- } \\
\text { blicas y ONGs para capacita- } \\
\text { ción y promoción de nuevas } \\
\text { acciones impulsadas por la } \\
\text { municipalidad, por ejemplo, } \\
\text { la feria de la Panela. } \\
\text { - Desarrollo de infraestructu- } \\
\text { ra y proyectos turísticos en } \\
\text { el municipio, en coordinación } \\
\text { con el MITUR para brindarle } \\
\text { visibilidad turística a Santa } \\
\text { María Ostuma. }\end{array}$ & $\begin{array}{l}\text { - Desarrollo de una legis- } \\
\text { lación propia que poten- } \\
\text { cie el cultivo de la región } \\
\text { y proteja el medio am- } \\
\text { biente. } \\
\text { - Aprovechamiento de } \\
\text { la integración con ALN y } \\
\text { CODENOL para desarro- } \\
\text { llar una fumigadora o con- } \\
\text { tratar servicios de fumiga- } \\
\text { ción en toda la región. }\end{array}$ \\
\hline
\end{tabular}




\section{DEBILIDADES}

DEFINICIÓN DE

ESTRATEGIAS DE

REORIENTACIÓN (DO)
DEFINICIÓN DE

ESTRATEGIAS DE

SUPERVIVENCIA (DA)
- Débil capacidad en el sector económico de las frutas para llegar al mercado.

- Poca atención para el desarrollo de talleres artesanales.

- Falta de conectividad con nuevas vías de acceso para llegar a nuevos mercados.

- No se cuenta con un mercado local.

- Falta de infraestructura adecuada para la venta de diferentes organizaciones asociativas.

- No se cuenta con campañas de promoción.

- Servicio de salud con horario restringido.

- Se comercializa la fruta externamente.

- Insumos agrícolas con precios elevados.

- No existe en el municipio un área o zona recreativa.

- No existen programas de prevención de la delincuencia.
- Desarrollo de nuevas vías de acceso para potenciar la distribución de la piña en otras zonas del país.

- Involucramiento de los jóvenes en los talleres artesanales, como estrategia para mantener la tradición cultural de la región.

- Desarrollo de alianzas con organismos internacionales para la creación y fomento de lugares de recreación y sano esparcimiento, por ej., canchas de fútbol, zonas infantiles, piscinas, etc.

- La municipalidad en coordinación con ONGs desarrollen proyectos culturales, deportivos, sociales con énfasis en el desarrollo de los jóvenes y evitar su involucramiento en actividades delictivas.
- Diversificación del cultivo en la zona, con lo que se obtendría mayor variedad frutal y se minimizaría el riesgo del deterioro ambiental.

- Reinvertir en los sitios turísticos actuales, para que el municipio sea más competitivo y atraer turismo nacional e internacional.

\section{Propuestas y perspectivas futuras}

El equipo de trabajo propone las siguientes acciones a desarrollar en el corto plazo y mediano plazo, con énfasis en la generación de empleo, incremento de los ingresos en el Municipio de Santa María Ostuma y consolidación del espíritu emprendedor de la comunidad:

- Organizar de forma conjunta con la Asociación de Paneleros
Ostumeños, la realización de la Primera Feria de la Panela Ostumeña, para que al igual que el modelo de la Feria de la Piña Ostumeña, se convierta en una tradición en el Municipio, que fomentará también el turismo.

- Dinamizar la economía local y regional, bajo el concepto de comercialización de los derivados de la caña de azúcar, con calidad y potencial de exporta- 
- ción y competitividad, a través de la consolidación de la red productor-vendedor.

- Garantizar la capacitación empresarial, así como las buenas prácticas en el procesamiento de la caña de azúcar, procurando una buena aceptación dentro del control de calidad de los productos procesados. Agregado a esto, también se debe fortalecer la infraestructura básica para el procesamiento de la caña de azúcar y medidas sanitarias acordes a la producción, que brinde garantía y confianza del producto final.

- Concebir y establecer la Ruta Turística de la Panela, arraigando o vinculando a esta la identidad que caracteriza a Santa María Ostuma y la Microrregión de Los Nonualcos (costumbres y tradiciones), así como los sitios turísticos con potencial en el Municipio y en la zona.

- En coordinación con la comuna, propiciar la inversión en el Municipio a través de la firma de un Asocio Público-Privado, que fortalezca la infraestructura física de la región, genere empleo y facilite el turismo en la zona, para el mejoramiento de las condiciones de vida de la población en la región. Las áreas claves que debe trabajar la Municipalidad de Santa María Ostuma, son:

- Pobreza y grupos vulnerables, ya que no debe perderse de vista la disminución y erradicación de la pobreza, así como atención a los grupos más vulnerables, principalmente los jóvenes que pueden ser atraídos por las pandillas o la delincuencia; y para quienes debe proponérseles programas de desarrollo emprendedor, cursos para el desarrollo de destrezas y capacitarles para el trabajo.

- Finanzas municipales, puesto que el dinero es de mucha importancia, y un buen manejo del mismo beneficia a la municipalidad como a la comunidad.

- Salud, principalmente en los niños y en las personas de la tercera edad, que son más vulnerables al ataque de los virus.

- Educación, deben mantenerse, ampliarse y abrirse nuevos centros escolares, en colaboración con el Gobierno Central, para que los jóvenes tengan todas las posibilidades de ingresar a estudiar, mantener una amplia cobertura y calidad educativa, ya que una población formada se vuelve productiva, y según estudios, se consigue romper el círculo de la pobreza (véase Formichella, M. M., 2009; Martinis, P., 2006); por lo tanto, la educación debe ser una apuesta de "Estado", en el cuál todos los involucrados participen activamente para su promoción y desarrollo.

Cerramos el presente artículo con una cita de Zapata (2008b), don- 
de plantea la visión para la Región de La Paz para el 2024: "La Región de La $\mathrm{Paz}$ es una plataforma logística, agroindustrial y turística, competitiva, en el marco de un desarrollo regional con identidad cultural propia y manejo sostenible de sus recursos". Si se trabaja de manera ordenada, creando redes de apoyo con alianzas estratégicas y el involucramiento "positivo" de todos los actores, consideramos que la visión planteada será un hecho en el año dos mil veinticuatro.

\section{Agradecimientos}

El equipo de trabajo quiere expresar sus profundos agradecimientos al Ing. José Fredy Cruz, investigador de la Universidad de El Salvador de la Zona Paracentral, San Vicente, por sus orientaciones técnicas en el desarrollo de la investigación de campo. A la Sra. Alcaldesa de Santa María Ostuma, Elsa Antonia Guevara, por facilitarnos espacio en la Alcaldía y apoyo en la logística al realizar las visitas técnicas, y a las autoridades de la Universidad Don Bosco, por el apoyo brindado al equipo investigador a nivel técnico y operativo.

\section{Bibliográfia}

Albuquerque, F. (2004). Desarrollo económico local y descentralización en América Latina. Revista de la CEPAL, 82, 157-171.

Alburquerque, F. (2015). Apuntes sobre la Economía del Desarrollo y el Desarrollo Territorial ¿Dónde situar el en- foque del Desarrollo Territorial dentro de los Estudios sobre el Desarrollo Económico?

Alcaldía Municipal de Santa María Ostuma (2008). Plan de Desarrollo Económico Local del municipio de Santa María Ostuma. Alcaldía Municipal de Santa María Ostuma.

(2011). Política Pública Municipal para el Fomento del Desarrollo Económico en el Municipio de Santa María Ostuma. Alcaldía Municipal de Santa María Ostuma y Cooperación Técnica Alemana (GTZ).

Asociación de Municipios Los Nonualcos (2010). Portafolio de proyectos de la ALN, La asociatividad una apuesta al desarrollo territorial, ALN, CODENOL, El Salvador.

Consejo de Desarrollo Económico Local de Los Nonualcos (2008). Estrategia de Desarrollo Económico Local de Los Nonualcos. Microregión de Los Nonualcos. Banco Interamericano de Desarrollo (BID), Cities Alliance, Fundación Nacional para el Desarrollo (FUNDE), Asociación de Municipios de Los Nonualcos (ALN) y Cooperación Técnica Alemana (GTZ).

Colectivo Feminista para el Desarrollo Local (2010). Diagnóstico Municipal de Santa María Ostuma. Colectivo Feminista para el Desarrollo Local. El Salvador.

Cruz, R.E.H., Gutiérrez, G.M.S., \& Digueros, J.A.L. (2015). Integración de una red de agroecoturismo en México y Guatemala como alternativa de desarrollo local. PASOS. Revista de Turismo y Patrimonio Cultural, 13(1).

Formichella, M. M. (2009). Una explicación de las trampas de pobreza: El circulo 
vicioso entre el nivel de educación y el nivel de ingresos. Estudios Económicos, 26(52), 49-80.

Gutiérrez Montoya, Guillermo A. (2013). El comportamiento emprendedor en El Salvador. Contexto, características y factores de éxito del emprendedor salvadoreño (pp. 178 y 194). Sevilla, Universidad Internacional de Andalucía.

Lara Coto, V.; Ponce, E., \& Salmerón, M. (2012). Diseño de un plan estratégico para la comercialización de la panela granulada y el dulce de atado de la Cooperativa ACOPANELA de R.L. Tesis de grado de la UES. San Salvador: Facultad de Ciencias Económicas, Universidad de El Salvador.
Martinis, P. (2006). Educación, pobreza e igualdad: del "niño carente" al "sujeto de la educación". En: P. Redondo, y P. Martinis (Comps.), Igualdad y educación: escrituras entre (dos) orillas (pp. 13-31). Buenos Aires: Del Estante Editorial.

Quant Dueñas, Iris María, \& Rodríguez Arrevillaga, Claudia Lorena (2011). Finanzas de proyectos; aplicabilidad a proyectos de gran envergadura en El Salvador. Tesis UES de Maestría, Santa Ana, El Salvador.

Zapata, Néstor (Coord.) (2008b). Sintesis del Plan de Desarrollo Territorial en la Región de La Paz, Proyecto PROA, GTZ, San Salvador.

Recepción: 04-09-2015 - Aceptación: 27-11-2015 